\title{
Robert P. Frankenthal Named Editor-in-Chief of Journal of Materials Research
}

Robert P. Frankenthal, materials consultant, has been named Editor-in-Chief of the Journal of Materials Research (JMR), an international publication of the Materials Research Society (MRS). The journal publishes original research articles and occasional invited reviews encompassing the synthesis, processing, characterization, properties, and theoretical description of materials. Frankenthal credits previous JMR editors-in-chief, Charles B. Duke (1986), Walter Brown (1987-1993), and Robert A. Laudise (1994-1998), for making the journal a "leading materials research publication, attracting outstanding contributions from around the world."

Frankenthal said that his goal in the coming years is to make JMR an even more relevant publication while maintaining its status as the premier archival journal in the materials research field. He described several initiatives already taken during his one-year tenure as acting editor-in-chief. "First, publishing several larger issues has eliminated the backlog of manuscripts awaiting publication," he said. "Second, we are shortening the time from manuscript submission to publication by actively reducing both the review time and the production time. Third, the entire contents of $J M R$ have recently been placed on-line on the MRS website." He said that JMR's progress results from the work of the editorial board including two distinguished associate editors in Europe and Japan and nearly 40 principal editors throughout the world, and the editorial staff at MRS headquarters.

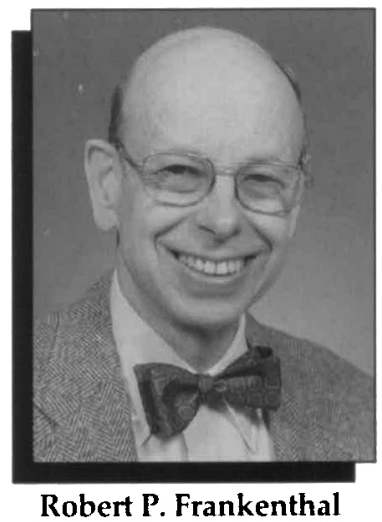

A year ago, Frankenthal was asked to serve as acting editor-in-chief while Laudise was ill. Frankenthal said, “Bob died several months later, bringing an end to almost five years of distinguished leadership to JMR." The Editorial Search Committee, chaired by James B. Roberto of Oak Ridge National Laboratory, recommended Frankenthal to succeed Laudise. Roberto said, "During the past year, Bob has provided outstanding leadership for $J M R$. He has initiated numerous improvements in editorial policy and Journal operations. This appointment will ensure the continuity of these improvements."

Frankenthal is a consultant on corrosion and reliability of electronic materials and devices. He was a Distinguished Member of Technical Staff at Bell Laboratories, Lucent Technologies (formerly AT\&T) in Murray Hill, New Jersey, before retiring in 1996. His research interests have included the corrosion and reliability of electronic materials and devices; the corrosion, passivation, and other surface properties of metals; physical and analytical electrochemistry; and surface analysis.

After receiving his $\mathrm{PhD}$ degree in analytical chemistry from the University of Wisconsin in 1956-following his tenure as a Procter and Gamble Fellow during the 1954-1955 academic year-Frankenthal joined the Applied Research Laboratory of U.S. Steel to work on the corrosion of tin and tin plate. In 1960, he transferred to U.S. Steel's E.C. Bain Laboratory for Fundamental Research, then joined AT\&T in 1972. Frankenthal's work has resulted in more than 100 publications and eight patents. He has co-edited six books.

Frankenthal has received numerous honors and awards including the W.R. Whitney Award from NACE (1997) and the H.H. Uhlig Award in Corrosion Science from the Corrosion Division, The Electrochemical Society (1989). He is a Fellow of The Electrochemical Society and NACE and was a T.H. Krengel Fellow at the Technion in Haifa, Israel (1998). He has served on numerous government, university, and other advisory panels. He has been active in The Electrochemical Society for more than 40 years, and was elected to serve as its President (1993-1994), Vice President (1990-1993), and Treasurer (1986-1990). He has also been active in NACE and the American Vacuum Society.

Pleased with Frankenthal's appointment, Roberto said, "JMR has an excellent team and a bright future."

\section{Arun Seraphin Appointed MRS/0SA Congressional Fellow for 1999-2000}

Arun Seraphin, research staff member in the Science and Technology Division at the Institute for Defense Analyses (IDA), has been named the 1999-2000 Materials Research Society/Optical Society of America Congressional Science and Engineering Fellow. His tenure begins in September. As a recipient of this one-year appointment sponsored jointly by MRS and OSA, Seraphin will work directly for a Member of Congress or on a Congressional Committee as a consultant on scientific and technical matters.

With a doctoral degree from the Department of Materials Science and Engineering from the Massachusetts Institute of Technology, a BA degree in political science from the State University of New YorkStony Brook, and three years' experience working for IDA, Seraphin views this Fellowship as a natural step in his pursuit

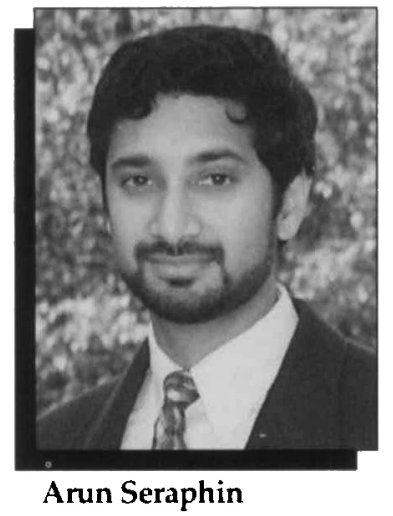

of a career in science and technology policy.

During his graduate studies, Seraphin focused his research on the processing and characterization of nanocrystalline semiconductor materials for optical switching and display applications. At IDA, he has worked on a number of projects for the Defense Advanced Research Projects Agency (DARPA), one of which was assisting DARPA in transitioning microelectromechanical systems (MEMS) into defense systems. In this project, Seraphin analyzed and evaluated opportunities for the use of MEMS in military applications such as medical technologies and missile guidance, he wrote and delivered briefings to numerous Department of Defense organizations, and he worked with academia and industry to explore the technical issues and potential defense applications of specific devices. Past MRS/OSA Fellow (1996-1997) and current Hill staffer Michal Freedhoff said, "Good communication skills are extremely important; a Congressional Fellow will not be of much use to nontechnical people on the Hill if he or she can't put technical information in terms 
that are both understandable and relevant to Congressional offices." Having worked with Seraphin in both the academic and political arena since 1995, she said, "Arun is very good at reducing complex scientific issues to the 'bottom-line' form that is valued on the Hill."

At IDA, Seraphin has also worked on international cooperative programs. He said, "America's science and technology base can be used to support foreign policy through international partnerships that build on pre-existing scientific community linkages. Innovative use of technology cooperation can help establish friendly relations and reduce political tension." $\mathrm{He}$ expects to bring to his position as Fellow his ability to analyze critical issues in science and technology and his social science and public policy experience needed "to see beyond the raw data and into the effects that policies will have on the broader socioeconomic situation."

Brian Holloway, MRS chair of the Congressional Fellow subcommittee, said, "MRS and OSA have worked hard to establish a tradition of extraordinary Congressional Fellows and I think Arun will push the bar even higher. His scientific training combined with his previous work experience should allow him to be very successful as a Fellow and very productive in any position that he chooses on Capitol Hill." Holloway was the 19971998 MRS/OSA Fellow and is currently an assistant professor at the College of William and Mary.

Seraphin is currently a member of the program committee for the SPIE Confer- ence on Smart Electronics and MEMS. He has served as secretary (1998-1999) and publicity co-chair (1997-1998) for the Washington, D.C. chapter of ASM International, and is also a member of MRS, the American Physical Society, the American Institute for Aeronautics and Astronautics, and the American Defense Preparedness Association. He is co-author of numerous technical articles and policy documents and briefings.

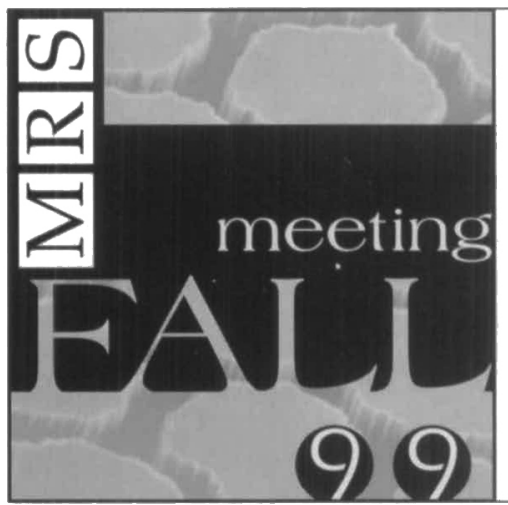

MRS Fall 1999 Meeting November 29-December 3, 1999 Boston, Massachusetts

For registration information, contact Materials Research Society at 724-779-3003 e-mail info.org. Check the MRS website for more details: www.mrs.org.

\section{Standard Vacuum Components}

\section{For All Applications}

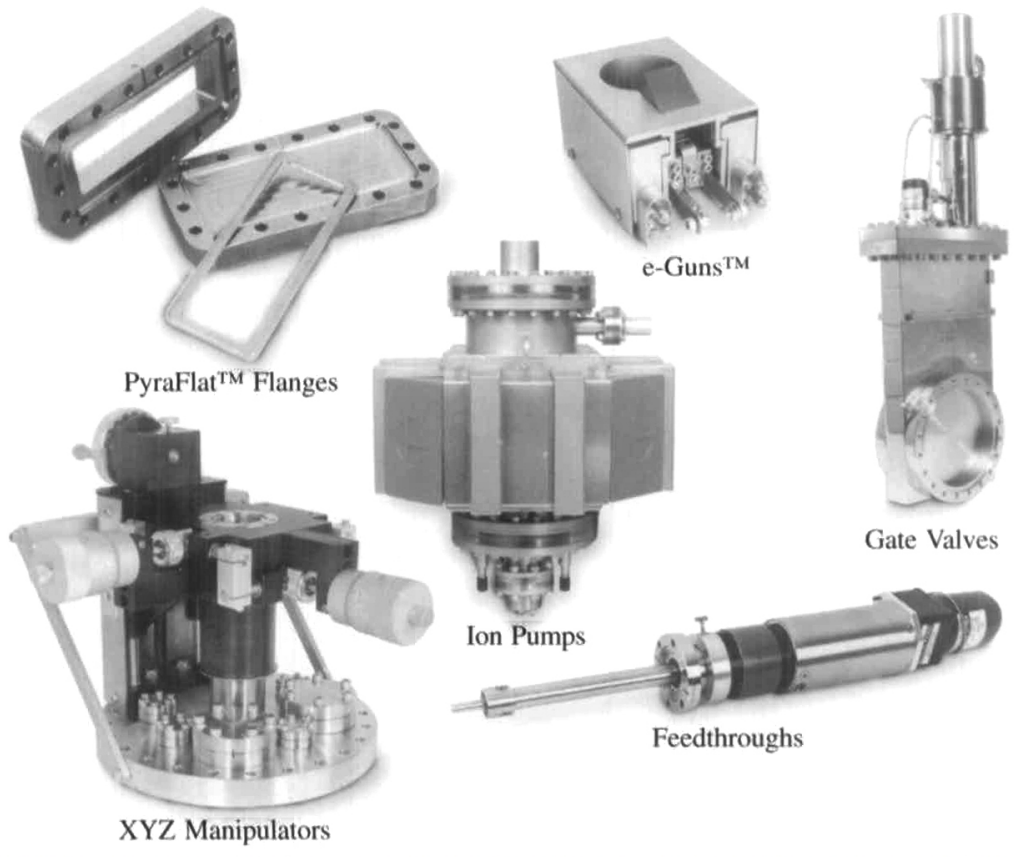

Thermionics offers a full line of vacuum components from ion pumps to xyz manipulators. What sets us apart from other companies is our ability to listen to and understand your specific vacuum requirements.

Whether you need a thermocouple gauge tube or a complete system, our engineers will ensure that you get exactly what you need.

For your free copy of our 340-page catalog, contact:

\section{(42) thermionics vacuum products}

\author{
231-B Otto Street \\ Port Townsend, WA 98368 \\ Toll-free: (800) 962-2310 ext. 143 \\ Fax: (360) 385-6617 \\ Internet: www.thermionics.com \\ Email: sales@thermionics.com
}

